\title{
Assessment of the knowledge and awareness of a sample of young researcher physicians on reporting guidelines and the EQUATOR network: A single center cross-sectional study
}

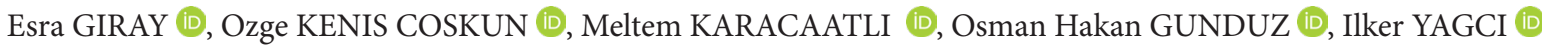 \\ Department of Physical Medicine and Rehabilitation, School of Medicine,Marmara University Training and Research Hospital,Istanbul, Turkey \\ Corresponding Author: Esra GIRAY_ E-mail: girayesra@hotmail.com, esra.giray@marmara.edu.tr
}

Submitted: 29.08.2019 Accepted: 27.10.2019

\begin{abstract}
Objective: This study aimed to investigate knowledge and awareness of a sample of young researcher physicians about reporting guidelines and the EQUATOR network.

Materials and Methods: One hundred young researcher physicians were enrolled for the study and evaluated using a questionnaire which assessed the level of usage and knowledge of reporting guidelines and the EQUATOR network.

Results: Thirty-eight percent of the participants were aware of the EQUATOR network. The most recognized reporting guidelines were CONSORT (32\%), PRISMA (35\%), and the least recognized ones were ARRIVE (12\%) GRRAS (12\%). The percentage of participants who were aware of the EQUATOR network and reporting guidelines were deficient. Seventy-three percent of the participants declared that they requested more information about reporting guidelines when they were asked whether they wished to be informed about reporting guidelines. There were statistically significant differences between specialists and residents regarding the level of knowledge on reporting guidelines and reporting guideline use except for PRISMA and SAMPL guidelines and their level of the desire to be informed about guidelines were similar. When participants whose publication number was above and below the mean of publications of all participants were compared, the level of reporting guidelines usage and knowledge of PRISMA, GRRAS were similar and both groups showed equal levels of desire to be informed about guidelines.

Conclusion: The use and awareness of the EQUATOR network and reporting guidelines are low among young researcher physicians. To improve the quality of manuscript writing and the acceptance rates, knowledge and awareness of the EQUATOR network and reporting guidelines should be increased among young physicians doing research.

Keywords: EQUATOR network, Reporting guidelines, Research
\end{abstract}

\section{INTRODUCTION}

Inaccurate and variable reporting of medical research can contribute to wasted research and sources [1]. As a result of poor methodology or improper reporting, published studies cannot often be replicated by researchers, compared with the existing literature, included in evidence synthesis or translated into clinical practice [1,2]. A reporting guideline is a simple, structured tool for health researchers to use while writing manuscripts. Reporting guidelines are statements that provide advice on how to report methods and results of a research.

Reporting guidelines are more than just some thoughts about what needs to be in an academic paper. Reporting guidelines are defined as: "A checklist, flow diagram, or structured text to guide authors in reporting a specific type of research, developed using explicit methodology". They provide a minimum set of items that are necessary for a transparent and clear account of what was done and what was found in a research study [2]. A reporting guideline provides a minimum list of the information needed to ensure a manuscript can be: understood by a reader, replicated by a researcher, used by a doctor to make a clinical decision, and included in a systematic review [2,3].

The Enhancing the QUAlity and Transparency Of Health Research (EQUATOR) network is an "umbrella" organization that brings together researchers, medical journal editors, peer reviewers, developers of reporting guidelines, research funding bodies and other collaborators with a mutual interest in improving the quality of research publications and of research itself. The EQUATOR network aims to achieve accurate, complete, and transparent reporting of all health research studies to support research reproducibility and usefulness, increase the value of health research and to minimize avoidable waste of financial and human investments in health research [2]. The EQUATOR network's online Library for Health Research Reporting currently lists almost 409 reporting guidelines [3]. Some of them are core guidelines for the most commonly conducted research types, and some of them are specialized guidelines which are

How to cite this article: Giray E, Kenis Coskun O, Karacaatli M, Gunduz O H, Yagci I. Assessment of the knowledge and awareness of a sample of young researcher physicians on reporting guidelines and the EQUATOR network: A single center cross-sectional study. Marmara Med J 2020;33: 1-6 doi: $10.5472 /$ marumj.682337 
specific to several research areas [4]. Popham et al. previously defined Consolidated Standards of Reporting Trials Statement for Reporting Randomized Controlled Trials (CONSORT); Transparent Reporting of Evaluations with Nonrandomised Designs (TREND) for nonrandomized trials; Strengthening the Reporting of Observational Studies in Epidemiology (STROBE), Preferred Reporting Items for Systematic Reviews and MetaAnalyses (PRISMA) and Standards for Reporting of Diagnostic Accuracy Studies (STARD) as core guidelines because they are frequently recommended guidelines by journals, have permanent websites, have explanations and examples that may be found in separate publications at the time of Popham et al.s preparation of their manuscript [4]. CONSORT for randomized controlled studies, PRISMA for systematic reviews and metaanalysis, Consensus-based Clinical Case Reporting (CARE) for case report, STROBE for observational studies, STARD for diagnostic accuracy studies, Animal Research: Reporting: In Vivo Experiments Guidelines (ARRIVE) for experimental animal studies and Statistical Analyses and Methods in the Published Literature (SAMPL) for statistical analysis are the basic guidelines that represent a range of study design.

The use of reporting guidelines and submission of checklists of the guidelines are promoted by the majority of high impact journals and journals which are indexed in the Science Citation Index or Science Citation Index Expanded [5,6]. Following them helps in preparing high-quality research, facilitates peer review, and increases the chances of manuscript acceptance [6]. Improved awareness and knowledge about reporting guidelines and the EQUATOR network may increase accurate reporting, thus providing adequate evidence to synthase and translate into clinical practice and increase acceptance rates. Several editorials are published to encourage researchers to use reporting guidelines. The level of knowledge and awareness of these reporting guidelines among authors, reviewers, and editors have been investigated in various scientific fields [2,3,5-9]. But, previously, only one study investigated the level of knowledge and awareness of these reporting guidelines among young physicians. However, the physicians' samples were limited to pediatricians [10].

The objective of this study was to investigate knowledge and awareness of a sample of young physicians engaged in research regarding reporting guidelines and the EQUATOR network. A further aim of this study was to increase young physicians' and readers' awareness about reporting guidelines and the EQUATOR network as well as increasing awareness of guidelines other than core guidelines.

\section{MATERIALS and METHODS}

One hundred young researcher physicians from Marmara University Training and Research Hospital were enrolled in this cross-sectional study undertaken between January 2019 and March 2019. Oral and written informed consents were obtained from all participants. Ethics committee approval was obtained from the Ethics Committee of Marmara University Medical School (approval number: 206). This study was reported in accordance with the checklist of items in the STROBE statement. Inclusion criteria were: (1) Being between the ages of 25-45; (2) Being a resident, specialist, fellowship program resident, fellowship specialist, assistant professor or associate professor; (3) Working less than 15 years in their respective field. Participants who were previously involved in a study investigating knowledge and awareness of reporting guidelines were excluded. One hundred young researcher physicians were interviewed. Knowledge and awareness on reporting guidelines were investigated via a questionnaire which was adopted from the survey invented by Oncel et al [10]. Data on age, sex, years in medical practice, professional degree, and specialty were recorded. Participants were requested to fill out a nonstandardized 28-item questionnaire. Participants were asked whether they had participated in any scientific study before the completion of the questionnaire, how many publications they have made; whether they had acted as a reviewer, and if yes, their numbers of reviews; whether they had used reporting guidelines in their publications; whether they had known about the EQUATOR network; which reporting guidelines they had known and whether they had used these as authors or reviewers; and whether they wanted to be informed about these guidelines.

\section{Statistical analysis}

IBM SPSS Statistics for Windows, Version 20,0 (Armonk, NY) was used to perform the analysis. The histogram and normality plots and Kolmogorov-Smirnov normality test were used to evaluate the distribution of variables before test selection. For the categorical data, descriptive analysis was performed and presented as frequency and percent values. For comparisons chi-square, Fisher's exact test and independent-samples t-test were used, and $\mathrm{p}<0.05$ was accepted as significant.

\section{RESULTS}

The recruitment flowchart is presented in Figure 1. A total of 110 participants were asked to complete the questionnaire, 10 of them were excluded, and 100 participants were enrolled and interviewed. Characteristics of the participants were presented in Table I. Thirty-eight percent of the participants were aware of the the EQUATOR network. The most recognized reporting guidelines were CONSORT (32\%), PRISMA (35\%), and the least recognized ones were ARRIVE $(12 \%)$ and GRRAS (12\%). The percentage of participants who were aware of the EQUATOR network and reporting guidelines were very low (Figure 2). Also, the rate of residents who knew about the EQUATOR Network and reporting guidelines were very low (Figure 3). Thirty-seven percent of the participants answered "Yes" to the question "Do you use reporting guidelines during publication of research?" When the participants were asked at which stages of production or publication of research they use reporting guidelines, $24 \%$ of the participants reported they used them while submitting their research to a journal, $14 \%$ of them used them during writing the manuscript, $12 \%$ of them reported that they used them while preparing research proposals for ethics review, $5 \%$ of the participants used reporting guidelines when determining study protocol. Only 19\% of the participants answered "Yes" to the question "Do you use reporting 
guidelines when serving as a reviewer for a scientific journal?" $73 \%$ of the participants declared that they requested more information about reporting guidelines when they were asked whether they wished to be informed about reporting guidelines. Participants were categorized into two groups as residents and medical specialists (specialists, fellowship residents, assistant professors and associate professors). When the specialist and residents were compared, there were statistically significant differences between them with regards to the level of knowledge of reporting guidelines and reporting guideline use except for PRISMA and SAMPL guidelines but their level of desire to be informed about guidelines were similar (Table II). When the participants with publications below and participants with publications above the mean number of publications were compared concerning their level of reporting guidelines usage and knowledge of PRISMA and GRRAS, the results of the groups were similar and both groups stated equal levels of desire to be informed about guidelines (Table III). When participants from Surgery and Internal Medicine were compared, participants from Surgery used reporting guidelines less than participants from Internal Medicine during publication of a research study (Table IV).

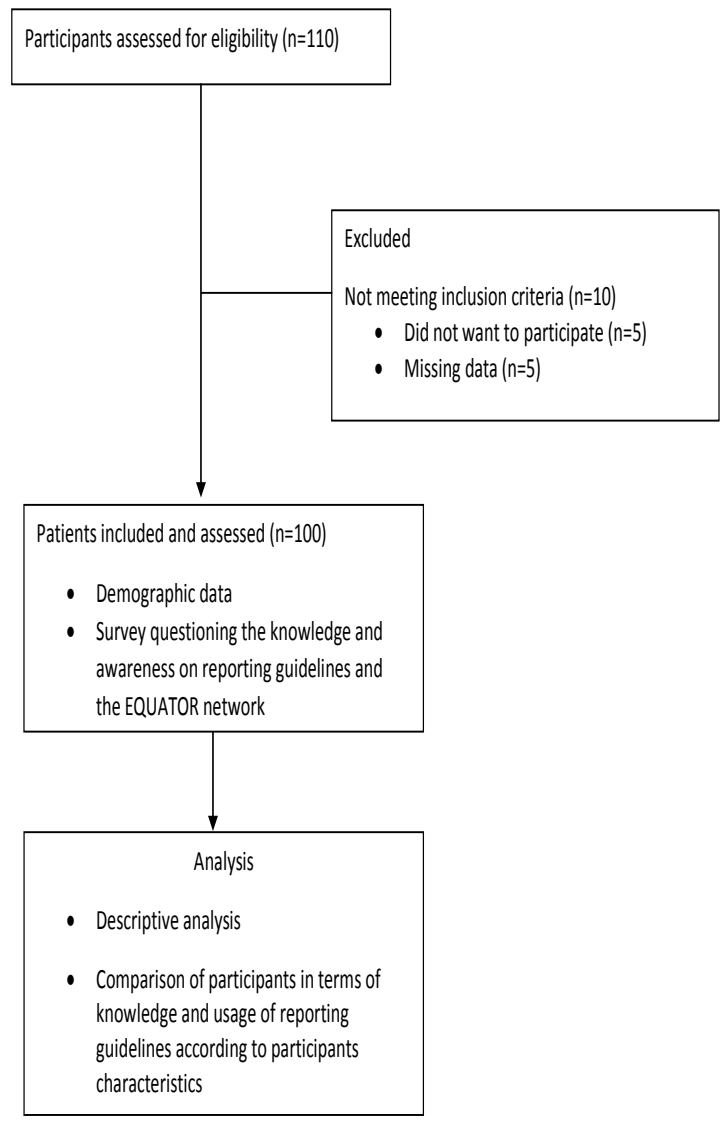

Figure 1. Flow chart of the study.

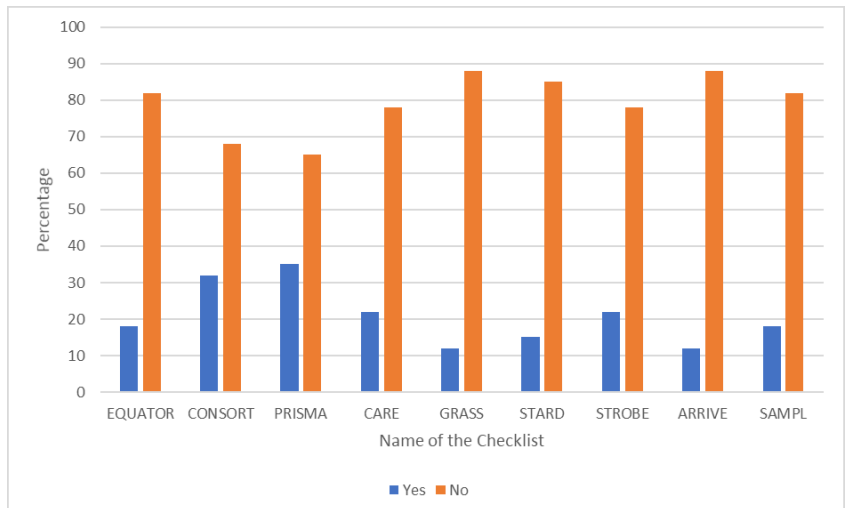

Figure 2. The percentage of participants who are aware of reporting guidelines and the EQUATOR network

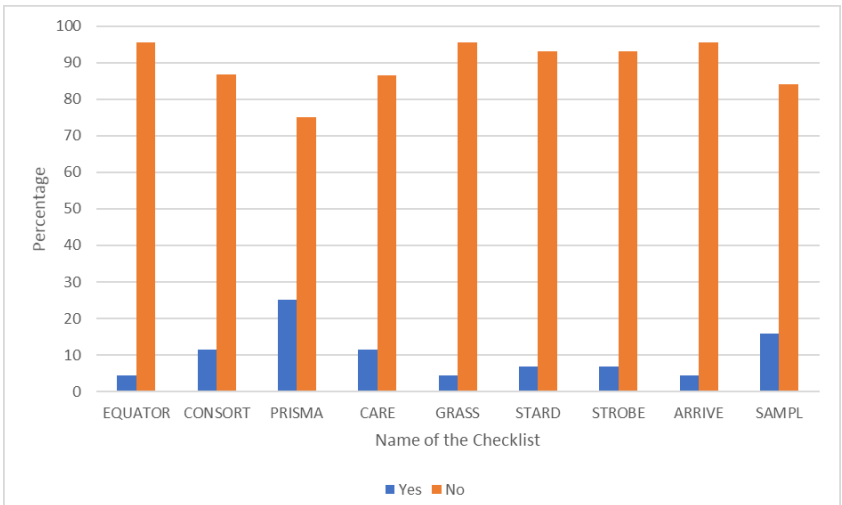

Figure 3. The percentage of residents who know about reporting guidelines and the EQUATOR network

Table I. Characteristics of the participants.

\begin{tabular}{|c|l|}
\hline Age & $32.69 \pm 5.91$ \\
\hline Gender (female/male) & $39 / 61$ \\
\hline Years in medical practice & $8.3 \pm 6.27$ \\
\hline Professional degree & $44 \%$ \\
\hline Resident & $23 \%$ \\
Specialist & $10 \%$ \\
Fellowship Resident & $11 \%$ \\
Assistant Professor & $12 \%$ \\
\hline Associate Professor & \\
\hline Medical specialty & $64 \%$ \\
Internal medicine & $36 \%$ \\
\hline Surgery & $87 \%$ \\
\hline Having participated in a research previously & $11.77 \pm 17.55$ \\
\hline Number of publications & $3.5 \pm 5.63$ \\
\hline Publications in Turkish & $8.05 \pm 12.92$ \\
\hline Publications in English & \\
\hline Publications & $64 \%$ \\
\hline Turkish & $65 \%$ \\
\hline English & $35 \%$ \\
\hline Previously acted as a reviewer &
\end{tabular}


Table II. Comparisons between specialists and residents

\begin{tabular}{|c|c|c|c|}
\hline & $\begin{array}{l}\text { Specialist } \\
(\mathrm{n}=56)\end{array}$ & $\begin{array}{l}\text { Resident } \\
(\mathrm{n}=44)\end{array}$ & p \\
\hline $\begin{array}{l}\text { Having participated in a research } \\
\text { previously }\end{array}$ & $54(96 \%)$ & $33(75 \%)$ & 0.002 \\
\hline Number of publications & $19.36 \pm 20.33$ & $2.11 \pm 3.24$ & 0.005 \\
\hline $\begin{array}{l}\text { Proportion of participant who have } \\
\text { publication in Turkish }\end{array}$ & $47(83 \%)$ & $17(38 \%)$ & 0.005 \\
\hline Number of publications in Turkish & & & 0.005 \\
\hline $\begin{array}{l}\text { Proportion of participant who have } \\
\text { publication in English }\end{array}$ & $52(92 \%)$ & $13(29 \%)$ & 0.005 \\
\hline Number of publications in English & $13.95 \pm 14.81$ & $0.55 \pm 0.98$ & 0.005 \\
\hline $\begin{array}{l}\text { Number of participants who use } \\
\text { reporting guidelines }\end{array}$ & $31(55 \%)$ & $6(13 \%)$ & 0.005 \\
\hline $\begin{array}{l}\text { Number of participants who use } \\
\text { reporting guidelines during publication } \\
\text { process }\end{array}$ & $38(67 \%)$ & $14(31 \%)$ & 0.005 \\
\hline $\begin{array}{l}\text { Number of participants who act as } \\
\text { reviewers }\end{array}$ & $34(60 \%)$ & $1(0.2 \%)$ & 0.005 \\
\hline $\begin{array}{l}\text { Number of participants who use } \\
\text { reporting guidelines as a reviewer }\end{array}$ & $17(30 \%)$ & $1(0.2 \%)$ & 0.005 \\
\hline $\begin{array}{l}\text { Number of participants who know the } \\
\text { EQUATOR Network }\end{array}$ & $16(28 \%)$ & $2(0.4 \%)$ & 0.002 \\
\hline $\begin{array}{l}\text { Number of participants who know } \\
\text { CONSORT }\end{array}$ & $27(48 \%)$ & $5(11 \%)$ & 0.005 \\
\hline $\begin{array}{l}\text { Number of participants who know } \\
\text { PRISMA }\end{array}$ & $24(42 \%)$ & $11(25 \%)$ & 0.06 \\
\hline Number of participants who know CARE & $17(30 \%)$ & $5(11 \%)$ & 0.02 \\
\hline $\begin{array}{l}\text { Number of participants who know } \\
\text { GRRAS }\end{array}$ & $10(17 \%)$ & $2(0.4 \%)$ & 0.04 \\
\hline $\begin{array}{l}\text { Number of participants who know } \\
\text { STARD }\end{array}$ & $12(21 \%)$ & $3(0.6 \%)$ & 0.04 \\
\hline $\begin{array}{l}\text { Number of participants who know } \\
\text { STROBE }\end{array}$ & $19(33 \%)$ & $3(0.6 \%)$ & 0.001 \\
\hline $\begin{array}{l}\text { Number of participants who know } \\
\text { ARRIVE }\end{array}$ & $10(17 \%)$ & $2(0.4 \%)$ & 0.04 \\
\hline $\begin{array}{l}\text { Number of participants who know } \\
\text { SAMPL }\end{array}$ & $11(19 \%)$ & $7(15 \%)$ & 0.63 \\
\hline $\begin{array}{l}\text { Number of participants who want } \\
\text { further information about reporting } \\
\text { guidelines }\end{array}$ & $45(80 \%)$ & $28(63 \%)$ & 0.06 \\
\hline
\end{tabular}

Table III. Comparisons between participants whose number of publications are under the mean of all participants and whose number of publications are over the mean of all participants

\begin{tabular}{|c|c|c|c|}
\hline & $\begin{array}{l}\text { Above mean } \\
(\mathbf{n}=33)\end{array}$ & $\begin{array}{l}\text { Below } \\
\text { mean } \\
(\mathrm{n}=67)\end{array}$ & $\mathbf{p}$ \\
\hline $\begin{array}{l}\text { Having participated in a research } \\
\text { previously }\end{array}$ & $33(100 \%)$ & $54(80 \%)$ & 0.007 \\
\hline Number of publications & $30.73 \pm 19.5$ & $2.43 \pm 2.84$ & 0.005 \\
\hline $\begin{array}{l}\text { Proportion of participant who have } \\
\text { publication in Turkish }\end{array}$ & $32(96 \%)$ & $32(47 \%)$ & 0.005 \\
\hline Number of publications in Turkish & $8.39 \pm 7.51$ & $1.09 \pm 1.5$ & 0.005 \\
\hline $\begin{array}{l}\text { Proportion of participant who have } \\
\text { publication in English }\end{array}$ & $33(100 \%)$ & $32(47 \%)$ & 0.005 \\
\hline Number of publications in English & $21.91 \pm 14.64$ & $1.22 \pm 1.78$ & 0.005 \\
\hline $\begin{array}{l}\text { Number of participants who use } \\
\text { reporting guidelines }\end{array}$ & $16(48 \%)$ & $21(31 \%)$ & 0.09 \\
\hline $\begin{array}{l}\text { Number of participants who } \\
\text { use reporting guidelines during } \\
\text { publication process }\end{array}$ & $22(66 \%)$ & $30(44 \%)$ & 0.04 \\
\hline $\begin{array}{l}\text { Number of participants who act as } \\
\text { reviewers }\end{array}$ & $27(81 \%)$ & $8(24 \%)$ & 0.005 \\
\hline $\begin{array}{l}\text { Number of participants who use } \\
\text { reporting guidelines as a reviewer }\end{array}$ & $11(33 \%)$ & $7(10 \%)$ & 0.01 \\
\hline $\begin{array}{l}\text { Number of participants who know } \\
\text { EQUATOR network }\end{array}$ & $11(33 \%)$ & $7(10 \%)$ & 0.005 \\
\hline $\begin{array}{l}\text { Number of participants who know } \\
\text { CONSORT }\end{array}$ & $18(54 \%)$ & $14(20 \%)$ & 0.001 \\
\hline $\begin{array}{l}\text { Number of participants who know } \\
\text { PRISMA }\end{array}$ & $16(48 \%)$ & $19(28 \%)$ & 0.05 \\
\hline $\begin{array}{l}\text { Number of participants who know } \\
\text { CARE }\end{array}$ & $12(36 \%)$ & $10(14 \%)$ & 0.02 \\
\hline $\begin{array}{l}\text { Number of participants who know } \\
\text { GRRAS }\end{array}$ & $7(21 \%)$ & $5(\% 7)$ & 0.05 \\
\hline $\begin{array}{l}\text { Number of participants who know } \\
\text { STARD }\end{array}$ & $8(24 \%)$ & $7(10 \%)$ & 0.06 \\
\hline $\begin{array}{l}\text { Number of participants who know } \\
\text { STROBE }\end{array}$ & $13(39 \%)$ & 9 & 0.003 \\
\hline $\begin{array}{l}\text { Number of participants who know } \\
\text { ARRIVE }\end{array}$ & $9(27 \%)$ & 3 & 0.001 \\
\hline $\begin{array}{l}\text { Number of participants who know } \\
\text { SAMPL }\end{array}$ & $10(30 \%)$ & 8 & 0.03 \\
\hline $\begin{array}{l}\text { Number of participants who } \\
\text { want further information about } \\
\text { reporting guidelines }\end{array}$ & $25(75 \%)$ & 48 & 0.66 \\
\hline
\end{tabular}


Table IV. Comparisons between participants from Surgery and Internal Medicine

\begin{tabular}{|c|c|c|c|}
\hline & $\begin{array}{l}\text { Internal } \\
\text { Medicine }(\mathrm{n}= \\
64)\end{array}$ & $\begin{array}{l}\text { Surgery } \\
(\mathrm{n}=36)\end{array}$ & $\mathbf{p}$ \\
\hline $\begin{array}{l}\text { Having participated in a research } \\
\text { previously }\end{array}$ & $57(89 \%)$ & $30(83 \%)$ & 0.41 \\
\hline Number of publications & $10.13 \pm 15.43$ & $14.69 \pm 20.71$ & 0.21 \\
\hline $\begin{array}{l}\text { Proportion of participant who have } \\
\text { publication in Turkish }\end{array}$ & $41(64 \%)$ & $23(63 \%)$ & 0.72 \\
\hline Number of publications in Turkish & $2.63 \pm 4$ & $5.06 \pm 7.55$ & 0.03 \\
\hline $\begin{array}{l}\text { Proportion of participant who have } \\
\text { publication in English }\end{array}$ & $44(68 \%)$ & $21(58 \%)$ & 0.54 \\
\hline Number of publications in English & $7.17 \pm 12.02$ & $9.61 \pm 14.43$ & 0.36 \\
\hline $\begin{array}{l}\text { Number of participants who use } \\
\text { reporting guidelines }\end{array}$ & $26(40 \%)$ & $11(30 \%)$ & 0.32 \\
\hline $\begin{array}{l}\text { Number of participants who } \\
\text { use reporting guidelines during } \\
\text { publication process }\end{array}$ & $39(60 \%)$ & $13(36 \%)$ & 0.02 \\
\hline $\begin{array}{l}\text { Number of participants who act as } \\
\text { reviewers }\end{array}$ & $22(34 \%)$ & $13(36 \%)$ & 0.41 \\
\hline $\begin{array}{l}\text { Number of participants who use } \\
\text { reporting guidelines as a reviewer }\end{array}$ & $12(18 \%)$ & $6(16 \%)$ & 0.39 \\
\hline $\begin{array}{l}\text { Number of participants who know } \\
\text { EQUATOR network }\end{array}$ & $14(21 \%)$ & $4(11 \%)$ & 0.18 \\
\hline $\begin{array}{l}\text { Number of participants who know } \\
\text { CONSORT }\end{array}$ & $21(32 \%)$ & $11(30 \%)$ & 0.81 \\
\hline $\begin{array}{l}\text { Number of participants who know } \\
\text { PRISMA }\end{array}$ & $22(34 \%)$ & $13(36 \%)$ & 0.86 \\
\hline $\begin{array}{l}\text { Number of participants who know } \\
\text { CARE }\end{array}$ & $16(25 \%)$ & $6(16 \%)$ & 0.33 \\
\hline $\begin{array}{l}\text { Number of participants who know } \\
\text { GRRAS }\end{array}$ & $9(14 \%)$ & $3(8 \%)$ & 0.39 \\
\hline $\begin{array}{l}\text { Number of participants who know } \\
\text { STARD }\end{array}$ & $10(15 \%)$ & $5(13 \%)$ & 0.81 \\
\hline $\begin{array}{l}\text { Number of participants who know } \\
\text { STROBE }\end{array}$ & $14(21 \%)$ & $8(22 \%)$ & 0.97 \\
\hline $\begin{array}{l}\text { Number of participants who know } \\
\text { ARRIVE }\end{array}$ & $7(10 \%)$ & $5(13 \%)$ & 0.66 \\
\hline $\begin{array}{l}\text { Number of participants who know } \\
\text { SAMPL }\end{array}$ & $12(18 \%)$ & $6(16 \%)$ & 0.79 \\
\hline $\begin{array}{l}\text { Number of participants who want } \\
\text { further information about reporting } \\
\text { guidelines }\end{array}$ & $49(76 \%)$ & $24(66 \%)$ & 0.28 \\
\hline
\end{tabular}

\section{DISCUSSION}

According to the results of the present study, the level of knowledge and awareness about reporting guidelines and the EQUATOR network among young physician researchers is low. Independent of being expert or resident or of the number of publications and of the medicine field, they all wanted to be informed about reporting guidelines and the EQUATOR network.

Recently, editors of journals from variable medical fields have published editorials to increase the awareness of researchers among reporting guidelines and aimed to promote transparent and accurate reporting of research. Also, adherence of journals to reporting guidelines have been investigated by checking author instructions of the journals [2,5,7-9,11]. In line with the results of the current study, the endorsement of reporting guidelines was found to be low in journals. Similar to the results of the current study, CONSORT and PRISMA were the most recommended guidelines that were found in author instructions $[8,9]$.

In a study conducted by Oncel et al [10], the rate of participants who were previously involved in a research was $63.8 \%$, which was found as $87 \%$ in our study and the rate of participants who have used reporting guidelines before was $26.6 \%$, which was found to be $37 \%$ in our study. In the present study, CONSORT (32\%) and PRISMA (35\%) were the most recognized guidelines. Similarly, Oncel et al., detected that the most known guidelines were PRISMA (10.3\%) and CONSORT (9.3\%) among a sample of pediatricians [10]. Marusic et al., assessed the endorsement of reporting guidelines in Rheumatology journals [8]. They detected that only ten Rheumatology journals among twentyeight journals recommended the use of reporting guidelines in instructions to authors in 2012, and the most recommended guideline was CONSORT. In another study, Kunath et al., investigated which reporting guidelines were recommended in journals publishing in the field of Urology [9]. Then it was detected that fourteen journals (25.5\%) among the fiftyfive journals mentioned at least one reporting guidelines in their author instructions. CONSORT was the most frequently recommended guideline in author instructions of Urology journals while reporting guidelines other than CONSORT was mentioned by the $6 \%$ of the journals publishing in the field of Urology. These results were compatible with the results of the present study that showed CONSORT was the most recognized reporting guideline, and the other was less known among young researchers. In 2014, Grindlay et al., assessed the knowledge and views of the Editors-in-Chief of veterinary journals [7]. Thirtysix of 68 editors (52\%) mentioned that they were aware of a reporting guidelines and 20 of these editors (35.1\%) stated that they refer reporting guidelines in their journals' instructions for authors. CONSORT and ARRIVE were the most recommended guidelines in instructions for authors. This result was opposite to the finding of the present study which found ARRIVE as one of the least known guidelines. This can be explained with the fact that ARRIVE is the reporting guideline for animal research, which is the leading research area of veterinary journals. When the editors were asked whether more information about guidelines would be useful, $88 \%$ of them answered "Yes" [7]. Similar to these results, all of the participants in this study wanted to be informed more about guidelines.

Reporting guidelines can be accounted as guides that may be used by reviewers and to evaluate the details of scientific studies objectively [10]. According to the results of the present study, the use of reporting guidelines by young physician researchers while serving as a reviewer for a scientific journal was found to be very infrequent. In line with the results of the present study, Oncel et al., reported that only 4 (4.5\%) of 224 pediatrician researchers stated that they use guidelines while reviewing an article [10].

Eighty-seven percent of the participants have previously been involved in research, but only $38 \%$ of participants of the study were aware of the EQUATOR network. In the study by Oncel 
et al.,63.8\% of the participants had participated in research and similarly, their level of knowledge and awareness about the EQUATOR network was low (5.8\% of the participants). Fuller et al., also demonstrated that familiarization with the EQUATOR network was low, $91 \%$ of the participants were unfamiliar with the EQUATOR network [1].

Oncel et al., compared pediatricians working at a university hospital to pediatricians working in a setting other than a university hospital in terms of their knowledge and awareness status. They did not determine any difference between them. Knowledge and awareness status were detected to be low in both. This study aimed to compare residents with specialists in terms of their knowledge and awareness about reporting guidelines. It also compared participants from Surgery and participants from Internal Medicine. A further analysis was made to compare participants with publications above or below the mean number of publications in terms of their knowledge and awareness about reporting guidelines. Although, knowledge of participants with higher number of publications and specialists' on well-recognized guidelines such as CONSORT and PRISMA was higher, they had lower level of knowledge about other specific guidelines such as GRRAS, STARD, SAMPL and the EQUATOR network. Their level of desire to gain knowledge about the EQUATOR network and reporting guidelines were similar regardless of being specialist or having higher number of publications. This study revealed the level of awareness and knowledge of young physician researchers. They all wanted to learn more about the EQUATOR network and reporting guidelines regardless of being a specialist or having a higher number of publications. The strength of this study is in exhibiting this reality. These findings may be used to inform further studies and increase attempts to improve knowledge of the EQUATOR network and reporting guidelines. We could not be able to compare characteristics of participants who were aware and not aware of the specific guidelines as the number of participants who were aware of the specific guidelines were very small. This can be viewed as the limitation of this study.

A systematic review of results using guidelines such as CONSORT may improve the quality of reporting [8]. Using reporting guidelines should not be seen as extra paperwork and useless time-consuming materials. We believe that increased awareness and knowledge of the EQUATOR network and reporting guidelines and adherence to reporting guidelines even at the protocol stage of research or review process of a scientific paper will be a milestone for increasing the scientific quality of studies $[2,6]$. Scholarly publishing in many fields has undergone an evolution. Guideline use while reporting studies has become mandatory in many areas of medicine [5]. Therefore, in conclusion, to elevate the quality of medical research, the level of knowledge of the EQUATOR network and reporting guidelines should be made higher, and young researchers should be encouraged to use them.

Declaration of interest: All authors declare that there are no conflicts of interest involved with the presented data.
Funding: The authors received no financial support for the research, authorship, and/or publication of this article.

\section{REFERENCES}

[1] Fuller T, Pearson M, Peters J, Anderson R. What affects authors' and editors' use of reporting guidelines? Findings from an online survey and qualitative interviews. PLoS ONE 2015;10:e0121585. doi: 10.1371/journal. pone.012.158.52015; 10:e0121585.

[2] Christensen R, Bliddal H, Henriksen MJAr, Therapy. Enhancing the reporting and transparency of rheumatology research: a guide to reporting guidelines. Arthritis Res Ter 2013;15:109. doi: 10.1186/ar4145.

[3] Simera I, Kirtley S, Altman DG. Reporting clinical research: guidance to encourage accurate and transparent research reporting. Maturitas 2012;72:84-7. doi: 10.1016/j. maturitas.2012.02.012.

[4] Popham K, Calo WA, Carpentier MY, et al. Reporting guidelines: optimal use in preventive medicine and public health. Am J Prev Med 2012;43:e31-e42. doi: 10.1016/j. amepre.2012.06.031

[5] Chan L, Heinemann AW, Roberts J. Elevating the quality of disability and rehabilitation research: mandatory use of the reporting guidelines.Am J Occup Ther 2014;68:127-9. doi: 10.5014/ajot.2014.682004.

[6] Rohrich RJ, Weinstein A. So, you want to improve your plastic surgery papers? Introducing PRS'friendly EQUATOR reporting guidelines. Plast Reconstr Surg 2015;136:205-8. doi: 10.1097/PRS.000.000.0000001393.

[7] Grindlay DJ, Dean RS, Christopher MM, Brennan ML. A survey of the awareness, knowledge, policies and views of veterinary journal Editors-in-Chief on reporting guidelines for publication of research. BMC Vet Res 2014;10 doi: 10.1186/1746-6148-10-10.:

[8] Marušić A, Gasparyan AY, Kitas GD. Promoting transparent and accurate reporting of research studies in rheumatology: Endorsement of reporting guidelines in rheumatology journals. Semin Arthritis Rheum 2013;43:288-91. doi: 10.1016/j.semarthrit.2013.01.005

[9] Kunath F, Grobe HR, Ruecker G, Engehausen D, Antes G, Wullich B. Do journals publishing in the field of urology endorse reporting guidelines? A survey of author instructions. Urol Int 2012;88:54-9. doi: 10.1159/000332742

[10] Öncel EK, Başaranoğlu ST, Aykaç K, Kömürlüoğlu A, Akman AÖ, Kiran S. Knowledge and awareness of optimal use of reporting guidelines in paediatricians: A cross-sectional study. Turk Pediatri Ars 2018;53:163-8. doi: 10.5152/ TurkPediatriArs.2018.6167

[11] Gasparyan AY, Yessirkepov M, Voronov AA, Koroleva AM, Kitas GD. Updated editorial guidance for quality and reliability of research output. J Korean Med Sci 2018;33:e247. doi: 10.3346/jkms.2018.33.e247. e 